\title{
Is It Time to Adopt Vision Screening for Ophthalmology Residency Program Applicants?
}

\author{
Preston H. Blomquist, $\mathrm{MD}^{1}$ \\ ${ }^{1}$ Department of Ophthalmology, The University of Texas \\ Southwestern Medical Center, Dallas, Texas \\ Journal of Academic Ophthalmology 2014;7:e1-e2.
}

\begin{abstract}
Although standards of vision have been set to drive a car, a minimum standard has not been set to perform intraocular surgery. This dichotomy exists despite a general feeling among many educators of the importance of good vision in predicting the technical ability of the beginning microsurgeon. There have been barriers to implementing vision screening for ophthalmology residency applicants. Title I of the Americans With Disabilities Act of 1990 (ADA) covers employers with 15 or more employees and prohibits discrimination of qualified individuals with disabilities in recruitment, hiring, promotions, training, pay, social activities, and other privileges of employment. ${ }^{1}$ ADA Title I restricts the questions that can be asked about an applicant's disability before a job offer is made and requires reasonable accommodation be made, unless it results in undue hardship. Because of fears of running afoul of the ADA, many ophthalmology programs do not perform visual screening of residency applicants. It is time for the profession to set a minimum standard of vision to practice ophthalmology.
\end{abstract}

A 2001 workshop of surgeons from the United States and Europe were queried as to the attributes felt important in the selection of surgery resident candidates. ${ }^{2}$ In addition to cognitive factors and personality traits, innate dexterity, defined as the "strongest determining factor in the level of technical (operative) skills that the individual attains with training and experience," was identified as a critical attribute. Felt important to innate dexterity were spatial perception, hand-eye coordination, aiming, multilimb coordination, and hand-arm steadiness. At the Royal College of Surgeons in Ireland, all shortlisted candidates for higher surgical training undergo formal testing of both technical skills and fundamental abilities (including psychomotor skills, visuospatial ability, and depth perception). ${ }^{3}$

Testing would not be necessary if applicants self-selected themselves for surgical careers on basis of their dexterity. A study using laparoscopic virtual reality simulation found applicants significantly performed lower than their self-assessment of dexterity. ${ }^{4}$ Self-assessed dexterity tasks like video gaming, sports, artistic activities, and musical instruments were not predictive of performance on the simulator. Internal medicine interns scored higher than applicants to a general surgery program on three of four tasks. If there is no apparent self-selection for a surgical career based on actual surgical skills, one needs a way to assess technical proficiency of applicants.

So what visual factors are important in determining the technical ability of a microsurgeon? Stereopsis would seem to be an obvious place to start. We know high-grade stereopsis is essential in skilled precision grasping. ${ }^{5}$ Amblyopes with deficient stereopsis have normal initial reaching and grip shaping, but deficient terminal reach and final grip closure and application. ${ }^{6}$ With the development of virtual simulators for intraocular surgery, we now have the capability to assess the effects of deficient stereopsis in a safe environment.

The Eyesi eye surgery simulator (VRmagic, Mannheim, Germany) provides a virtual reality environment that can teach basic skills, measure tremor, and allow practice of some of the steps of intraocular surgery. Construct validity for the Eyesi antitremor, forceps training, and capsulorhexis modules has been established. ${ }^{7-9}$ Waqar et al studied 30 junior doctors with no previous ophthalmic surgical experience. ${ }^{10}$ Subjects undertook four attempts of the level 4 forceps module binocularly and another four monocularly to simulate an acute loss of stereopsis. Significant findings $(p<0.05)$ included a decrease in average total score and increases in average corneal area injured, average lens area injured, and average time taken when the simulation was performed monocularly compared with binocularly. The authors did note that 3 of the 30 subjects had a statistically significant increase in the total score when performed monocularly. This may be a function of study design, however. The increase in scores when performed monocularly was mainly due to quicker time or decreased odometer scores, perhaps due to the monocular trials being

Address for correspondence

Preston H. Blomquist, MD,

Department of Ophthalmology, University of Texas Southwestern Medical Center, 5323 Harry Hines DOI http://dx.doi.org/ Blvd., Dallas, TX 75390-9057 10.1055/s-0034-1396086. (e-mail: preston.blomquist@ＩSSN 2164-7879.
Copyright @ 2014 by Thieme Medical Publishers, Inc., 333 Seventh Avenue, New York, NY 10001, USA. Tel: +1(212) 584-4662.

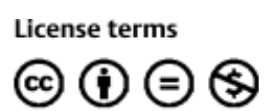

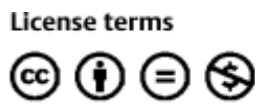

utsouthwestern.edu). 
done after the binocular attempts, and at the cost of increased injury to the lens.

Sachdeva and Traboulsi studied 21 subjects with absent or deficient stereoacuity ( $\leq 100$ seconds of arc) and 21 control subjects with stereoacuity of 40 to 60 seconds of arc. ${ }^{11}$ Individuals with normal stereoacuity performed better than those with deficient stereoacuity $(p<0.001)$. Additional attempts did not result in improved performance by the study group compared with the control group. While there were some subjects with normal stereoacuity that performed worse than the study group, this indicates that there are other factors in addition to stereopsis that determines technical ability for intraocular surgery. Future virtual simulator studies may elucidate these factors (visual acuity, color vision, and steadiness of hand) and determine acceptable levels of diminished function.

Testing of stereoacuity would seem to be a reasonable measure for those applying to ophthalmology residency. We aim to train those who will excel in our profession, not just be adequate. We do our applicants a disservice when we allow them to start a microsurgical residency if they lack the physical prerequisites to successfully complete it. We are fortunate to attract exceedingly bright and talented people to our profession. However, I advise medical students with poor stereopsis to find another career beside ophthalmology, a career in which they can flourish and excel, not just be adequate at best.

Finally, the argument is made that there are ophthalmic surgeons in practice with deficient stereoacuity. Should we stop them from operating? As a profession, we should regulate ourselves in the best interests of the public. Maintenance of certification was introduced by the American Board of Ophthalmology to provide assurance to the public that diplomates "keep current in information and skills and practice in a contemporary and safe manner."12 Yet the only check of surgical competency in the current certification process is a statement by the applicant's residency program director and chair at the time of original certification that the applicant can practice competently and independently. Vision testing for factors found to be related to technical ability could be performed as part of the maintenance of certification process. For those who fail the vision test, surgical competence could be tested (e.g., testing on a virtual simulator or independent review of surgical outcomes).

As reliable predictors of technical ability are validated, they should be tested in the application process to identify those individuals with the greatest potential to excel. This is no different than the use of standardized test scores and academic grade point averages to try assess an applicant's cognitive potential. As a profession, we owe it to the public to produce the highest quality ophthalmic surgeons in our training programs. The implementation of vision screening for applicants based on evidenced-based standards fulfills the profession's duty to the public without violating the ADA.

\section{Conflict of Interest}

The author has no proprietary or financial interest in the material discussed in this article.

\section{Funding}

This study was supported, in part, by an unrestricted research grant from Research to Prevent Blindness, Inc., New York.

\section{References}

142 U.S.C. $\S \S 12111-12117$ [Title 42 - The public health and welfare, Chapter 126 - Equal opportunity for individuals with disabilities, Subchapter I - Employment]

2 Cuschieri A, Francis N, Crosby J, Hanna GB. What do master surgeons think of surgical competence and revalidation? Am J Surg 2001;182(2):110-116

3 Gallagher AG, Leonard G, Traynor OJ. Role and feasibility of psychomotor and dexterity testing in selection for surgical training. ANZ J Surg 2009;79(3):108-113

4 Panait L, Larios JM, Brenes RA, et al. Surgical skills assessment of applicants to general surgery residency. J Surg Res 2011;170(2): 189-194

5 Melmoth DR, Finlay AL, Morgan MJ, Grant S. Grasping deficits and adaptations in adults with stereo vision losses. Invest Ophthalmol Vis Sci 2009;50(8):3711-3720

6 Grant S, Melmoth DR, Morgan MJ, Finlay AL. Prehension deficits in amblyopia. Invest Ophthalmol Vis Sci 2007;48(3):1139-1148

7 Mahr MA, Hodge DO. Construct validity of anterior segment antitremor and forceps surgical simulator training modules: attending versus resident surgeon performance.J Cataract Refract Surg 2008; 34(6):980-985

8 Privett B, Greenlee E, Rogers G, Oetting TA. Construct validity of a surgical simulator as a valid model for capsulorhexis training. J Cataract Refract Surg 2010;36(11):1835-1838

9 Le TD, Adatia FA, Lam WC. Virtual reality ophthalmic surgical simulation as a feasible training and assessment tool: results of a multicentre study. Can J Ophthalmol 2011;46(1):56-60

10 Waqar S, Williams O, Park J, Modi N, Kersey T, Sleep T. Can virtual reality simulation help to determine the importance of stereopsis in intraocular surgery? Br J Ophthalmol 2012;96(5):742-746

11 Sachdeva R, Traboulsi EI. Performance of patients with deficient stereoacuity on the EYESi microsurgical simulator. Am J Ophthalmol 2011;151(3):427-33.e1

12 American Board of Ophthalmology. Frequently asked questions about MOC. Available at: http://abop.org/maintain-certification/ faq/. Accessed February 1, 2013 